\title{
Differential effects of insulin-like growth factor binding protein-6 (IGFBP-6) on migration of two ovarian cancer cell
} lines

\author{
Zhiyong Yang ${ }^{1}$ and Leon A. Bach ${ }^{1,2} *$ \\ ${ }^{1}$ Department of Medicine (Alfred), Monash University, Prahran, VIC, Australia \\ ${ }^{2}$ Department of Endocrinology and Diabetes, Alfred Hospital, Melbourne, VIC, Australia
}

\section{Edited by:}

Haim Werner, Tel Aviv University, Israel

Reviewed by:

Andrea Morrione, Thomas Jefferson University, USA

Ilan Bruchim, Meir Medical Center, Israel

\section{*Correspondence:}

Leon A. Bach, Department of Endocrinology and Diabetes, Alfred Hospital, Commercial Road, Melbourne, VIC 3004, Australia e-mail:leon.bach@monash.edu
Introduction: IGFBP-6 inhibits angiogenesis as well as proliferation and survival of rhabdomyosarcoma cells. However, it promotes migration of these cells in an IGF-independent manner. The IGF system is implicated in ovarian cancer, so we studied the effects of IGFBP-6 in ovarian cancer cells.

Methods: The effects of wild type (wt) and a non-IGF-binding mutant $(\mathrm{m})$ of IGFBP-6 on migration of HEY and SKOV3 ovarian cancer cells, which, respectively, represent aggressive and transitional cancers, were studied. ERK and JNK phosphorylation were measured by Western blotting.

Results: IGF-II, wt-, and mIGFBP-6 each promoted SKOV3 cell migration by 77-98\% $(p<0.01)$. In contrast, IGF-II also increased HEY cell migration to $155 \pm 13 \%$ of control $(p<0.001)$, but wt-IGFBP-6 and mIGFBP-6 decreased migration to $62 \pm 5$ and $66 \pm 3 \%$, respectively $(p<0.001)$. In these cells, coincubation of IGF-II with wt but not mIGFBP-6 increased migration. MAP kinase pathways are involved in IGFBP-6-induced rhabdomyosarcoma cell migration, so activation of these pathways was studied in HEY and SKOV3 cells. Wt and mIGFBP-6 increased ERK phosphorylation by $62-99 \%$ in both cell lines $(p<0.05)$. Wt-IGFBP-6 also increased JNK phosphorylation by $139-153 \%$ in both cell lines $(p<0.05)$, but the effect of mIGFBP- 6 was less clear. ERK and JNK inhibitors partially inhibited the migratory effects of wt and mIGFBP-6 in SKOV3 cells, whereas the ERK inhibitor partially restored wt and mIGFBP-6-induced inhibition of HEY cell migration. The JNK inhibitor had a lesser effect on the actions of wtIGFBP-6 and no effect on the actions of mIGFBP-6 in HEY cells.

Conclusion: IGFBP-6 has opposing effects on migration of HEY and SKOV3 ovarian cancer cells, but activates MAP kinase pathways in both. Delineating the pathways underlying the differential effects on migration will increase our understanding of ovarian cancer metastasis and shed new light on the IGF-independent effects of IGFBP-6.

Keywords: insulin-like growth factor, insulin-like growth factor binding protein-6, ovarian cancer, migration, MAP kinase

\section{INTRODUCTION}

The insulin-like growth factor (IGF) system has a key role in normal growth and development (1). IGF-I is regulated by growth hormone and mediates many of its actions, whereas both IGFI and IGF-II stimulate proliferation, survival, and migration of many cell types. Dysregulation of the IGF system is implicated in many disease processes including cancer, and there has been considerable interest in recent years in developing IGF inhibitors as therapeutic agents (2). However, clinical trials of these inhibitors has been disappointing, and current strategies include understanding mechanisms of resistance as well as finding biomarkers of IGF responsiveness that will permit optimized targeting of these agents.

Insulin-like growth factor actions are regulated by a family of six high affinity binding proteins (IGFBP $1-6)(3,4)$. Of these, IGFBP- 6 is characterized by a 50 -fold binding preference for IGF-II over IGF-I, conferring specificity in inhibiting IGF-II actions (57). Most IGFBPs also have IGF-independent actions, and we have shown in recent years that IGFBP-6 inhibits angiogenesis (8) as well as promoting migration of rhabdomyosarcoma and colon cancer cells in an IGF-independent manner $(9,10)$. Further, we identified cell surface prohibitin-2 as a protein that binds IGFBP-6 and is required for its effects on cell migration (11).

Ovarian cancer is the second most common gynecological malignancy after uterine cancer but the most common cause of gynecological cancer death in Australia (12). In the United States, ovarian cancer is the eighth most common cancer and the fifth leading cause of cancer death in women (13). The diagnosis of ovarian cancer is often delayed because it presents with nonspecific symptoms, so that it has metastasized at presentation. Because of this, 5 -year-survival is $43 \%$. The IGF system is implicated in ovarian cancer, and both IGF ligands and the IGF-I 
receptor are expressed in this malignancy (14). In particular, IGF2 gene expression was 300-fold higher in ovarian cancer tissue than in normal ovarian tissue and expression was higher in advanced stage poor prognosis cancers (15). IGFs have also been shown to stimulate ovarian cancer cell invasion, proliferation, and angiogenesis (16).

IGFBP-6 is commonly expressed at low levels in ovarian cancers (17). A single microarray study showed that IGFBP-6 mRNA levels were lower in ovarian cancer tissue compared with noncancerous tissue (18); this may reflect derepression of IGF-II action by decreased IGFBP-6, but levels were not confirmed in an independent assay. Small studies of IGFBP-6 in serum of patients with ovarian cancer are inconsistent $(19,20)$, which may reflect methodological differences. The aim of this study was to determine the effects of IGFBP- 6 on migration of HEY, SKOV3, and OVCAR3 ovarian epithelial cancer cells, which, respectively, represent aggressive, transitional, and less aggressive tumors.

\section{MATERIALS AND METHODS \\ REAGENTS}

Wild-type (wt) IGFBP-6 and a non-IGF-binding mutant (Pro ${ }^{93} / \mathrm{Ala}, \mathrm{Leu}^{94} / \mathrm{Ala}, \mathrm{Leu}^{97} / \mathrm{Ala}, \mathrm{Leu}^{98} / \mathrm{Ala}$ ) were expressed as $\mathrm{His}_{6}$-tagged proteins in E. coli, purified by Ni-NTA chromatography, dialyzed against cell culture medium, and then stored in aliquots at $-80^{\circ} \mathrm{C}$ as previously described (9). Phosphatase inhibitor mixtures 1 and 2 and signaling pathway inhibitors PD98095 (for ERK1/2) and SP600125 (for JNK) were from Sigma-Aldrich. Complete EDTA-free protease inhibitor mixture tablets were from Roche Applied Science. Antisera to phosphoERK1/2 (Thr-204/Tyr-204), phospho-JNK (Thr-181/Tyr-185), total ERK1/2 and JNK, and horseradish peroxidase-conjugated donkey anti-rabbit IgG were from Genesearch (Arundel, Australia). $\beta$-actin and PHB2 antisera were from Millipore (North Ryde, Australia). SeeBlue Plus2 molecular weight markers were obtained from Invitrogen.

\section{CELL CULTURE}

HEY, SKOV3, and OVCAR-3 cells, which, respectively, represent aggressive, transitional, and less aggressive human ovarian cancers (21), were used in the study. HEY cells are mostly mesenchymal with a typical molecular signature ( $\mathrm{N}$-cadherin and vimentin positive, E-cadherin negative). SKOV3 cells are moderately epithelial, with a flattened cobblestone appearance but a mesenchymal molecular signature ( $\mathrm{N}$-cadherin and vimentin positive, E-cadherin negative). OVCAR-3 cells are slowest growing and are epithelial by morphology and their molecular signature (E-cadherin positive, vimentin negative). All cell lines were cultured in a 1:1 mixture of Medium 199 and MCDB 105 (Sigma-Aldrich), supplemented with $2 \mathrm{mM}$ L-glutamine, 100 units $/ \mathrm{ml}$ penicillin, $100 \mu \mathrm{g} / \mathrm{ml}$ streptomycin, $0.25 \mu \mathrm{g} / \mathrm{ml}$ amphotericin $\mathrm{B}$, and either $10 \%$ heat inactivated bovine calf serum (complete culture medium, CCM) or $0.05 \%$ BSA (serum-free medium, SFM). Cells were seeded at $37^{\circ} \mathrm{C}, 5 \% \mathrm{CO}_{2}$ for $24-48 \mathrm{~h}$ until they reached $70 \sim 80 \%$ confluence, followed by serum starvation for $16 \mathrm{~h}$, and then subjected to treatments for various times as specified, without or with IGFBP-6 (wt or mutant, $1 \mu \mathrm{g} / \mathrm{ml}$ ), IGF-II $(100 \mathrm{ng} / \mathrm{ml})$, and/or pathway inhibitors $(30 \mu \mathrm{M})$.

\section{CELL PROLIFERATION ASSAY}

Cell number was measured after $72 \mathrm{~h}$ in serum-free medium using an MTT assay as previously described (22).

\section{CELL MIGRATION ASSAY}

Migration assays were performed using a 48-well microchemotaxis chamber (Neuroprobe, Cabin John, MD) as described previously (9). Wt or mIGFBP-6 $(1 \mu \mathrm{g} / \mathrm{ml})$ or IGF-II $(100 \mathrm{ng} / \mathrm{ml})$ in SFM were added to the bottom well of the chamber. Polycarbonate filters $(12 \mu \mathrm{m}$ pore size, coated with $100 \mu \mathrm{g} / \mathrm{ml}$ gelatine in $10 \mathrm{mM}$ acetic acid at room temperature for $30 \mathrm{~min}$ ) were placed over the bottom wells, and cells $\left(5 \times 10^{4}\right.$ cells/well $)$ in SFM were seeded in the top wells. In some experiments, pathway inhibitors PD98095 or SP600125 $(30 \mu \mathrm{M})$ in SFM were added to both bottom and top chambers. After $16 \mathrm{~h}$, the filter was removed, fixed with $100 \%$ methanol for $5 \mathrm{~min}$, and stained with $0.5 \%$ crystal violet, $50 \%$ methanol for $20 \mathrm{~min}$. The filter was then washed in water to remove excess dye and unbound cells. After mounting the filter on a glass slide, non-migrated cells on the top side of the filter were completely removed. Three random fields per well were photographed, and migrating cells were counted using ImageJ software (National Institutes of Health, Bethesda, MD, USA) ${ }^{1}$. Each data point represents four to seven replicates.

\section{PHOSPHORYLATION ASSAYS}

Phosphorylation of MAP kinase pathway proteins was examined by Western blotting analysis. After treatment with wt- or mIGFBP- 6 for $10 \mathrm{~min}$, cells were washed with cold PBS and lysed in $10 \mathrm{mM}$ Tris- $\mathrm{HCl}$ ( $\mathrm{pH}$ 8.0), $0.1 \mathrm{M} \mathrm{NaCl}, 1 \mathrm{mM}$ EDTA, $1 \%$ Triton $\mathrm{X}-100$ containing protease inhibitors. Lysates were centrifuged at $13,000 \mathrm{rpm}$ for $5 \mathrm{~min}$, supernatants collected and protein concentration determined. Proteins $(60 \mu \mathrm{g} / \mathrm{lane})$ were separated by SDS-10\% PAGE and transferred onto nitrocellulose membranes. Western blotting analyses were performed using antibodies against phospho-ERK1/2 (1:2,000) or phospho-JNK (1:1,000). Following an enhanced chemiluminescence reaction, membranes were exposed to X-ray film. The membranes were then reprobed with antisera to total ERK1/2 $(1: 2,000)$ or JNK $(1: 1,000)$, and finally $\beta$ actin $(1: 10,000)$. Band intensities were quantitated using ImageJ software.

\section{STATISTICS}

Results are shown as mean \pm SEM of three to nine independent experiments as indicated. Data were analyzed by one-way or twoway ANOVA as appropriate followed by Fisher's PLSD test to compare individual treatments.

\section{RESULTS}

\section{IGFBP-6 HAS DIFFERENTIAL EFFECTS ON MIGRATION OF SKOV3 AND HEY OVARIAN CANCER CELLS}

Initially, the effects of IGF-II and wt or mIGFBP-6 on proliferation of ovarian cancer cells were studied. However, none of these proteins had any effect on proliferation (results not shown). Cell migration was then studied using a microchemotaxis chamber.

\footnotetext{
${ }^{1}$ http://imagej.nih.gov/ij
} 


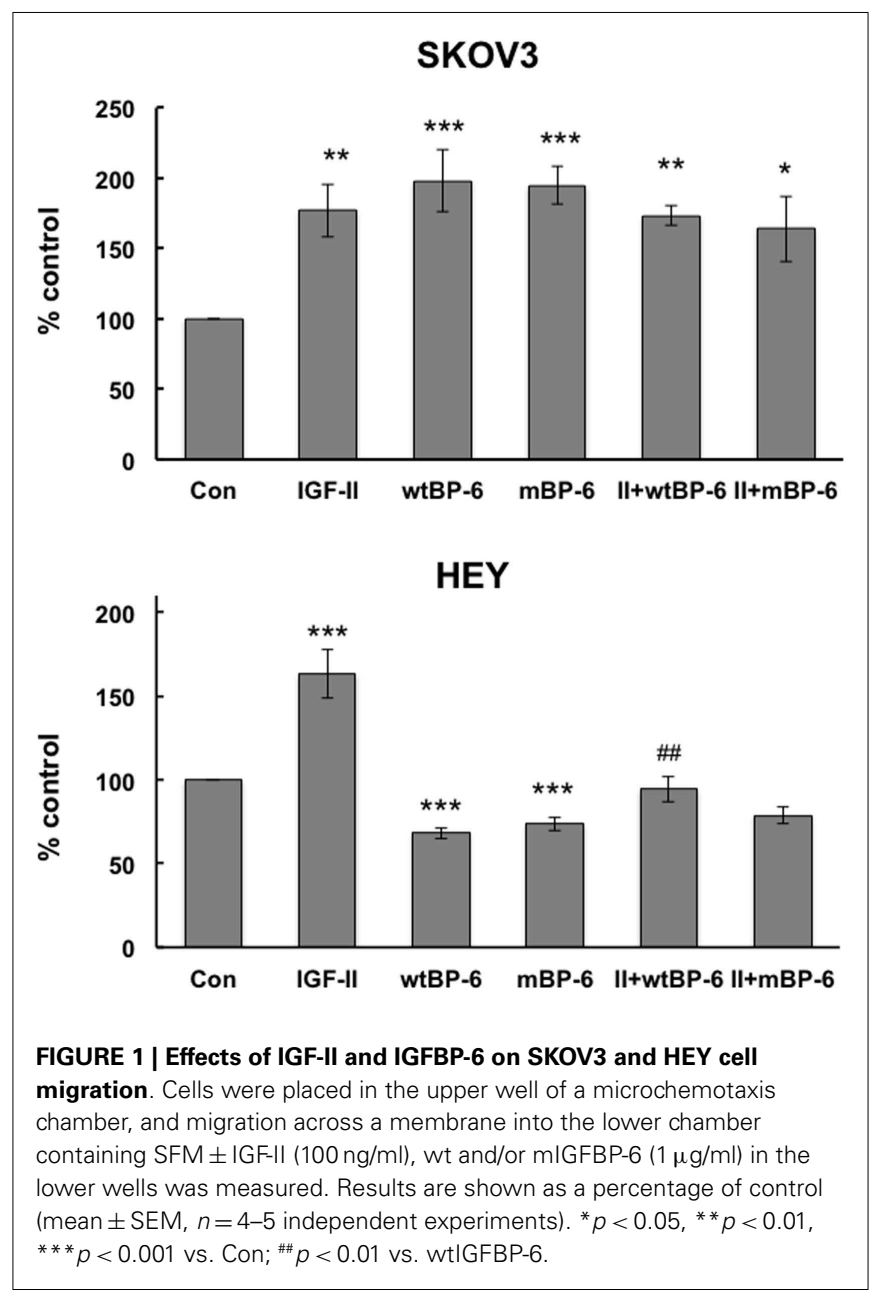

SKOV 3 cell migration was increased by IGF-II ( $177 \pm 19 \%$ of control, $p<0.01)$, wtIGFBP-6 $(198 \pm 22 \%$ of control, $p<0.001)$, and mIGFBP-6 (195 $\pm 13 \%$ of control, $p<0.001)$ (Figure 1). Coincubation of IGF-II with either wt or mIGFBP-6 had no additional effect on migration of these cells. Collectively, these results suggest that the effect of IGFBP-6 was IGF-independent.

Insulin-like growth factor-II also increased HEY cell migration to $155 \pm 13 \%$ of control $(p<0.001)$ but wtIGFBP- 6 and mIGFBP- 6 each decreased migration to $62 \pm 5$ and $66 \pm 3 \%$ of control, respectively $(p<0.001)$ (Figure 1). Coincubation of IGFII reversed the effect of wtIGFBP- 6 to $95 \pm 7 \%$ of control $(p<0.01$ wtIGFBP-6 vs. wtIGFBP-6 + IGF-II). In contrast, coincubation of IGF-II had no significant effect on the mIGFBP-6-induced decrease in migration. These results suggest that the effect of IGFBP-6 was IGF-dependent to some extent in these cells.

OVCAR-3 cells did not migrate under basal conditions or after incubation with IGF-II or IGFBP-6 (results not shown) and were not studied further.

\section{IGFBP-6 INCREASES MAP KINASE ACTIVATION IN OVARIAN CANCER CELLS}

We have previously shown that MAP kinase pathways are involved in IGFBP-6-induced rhabdomyosarcoma cell migration $(9,10)$, so

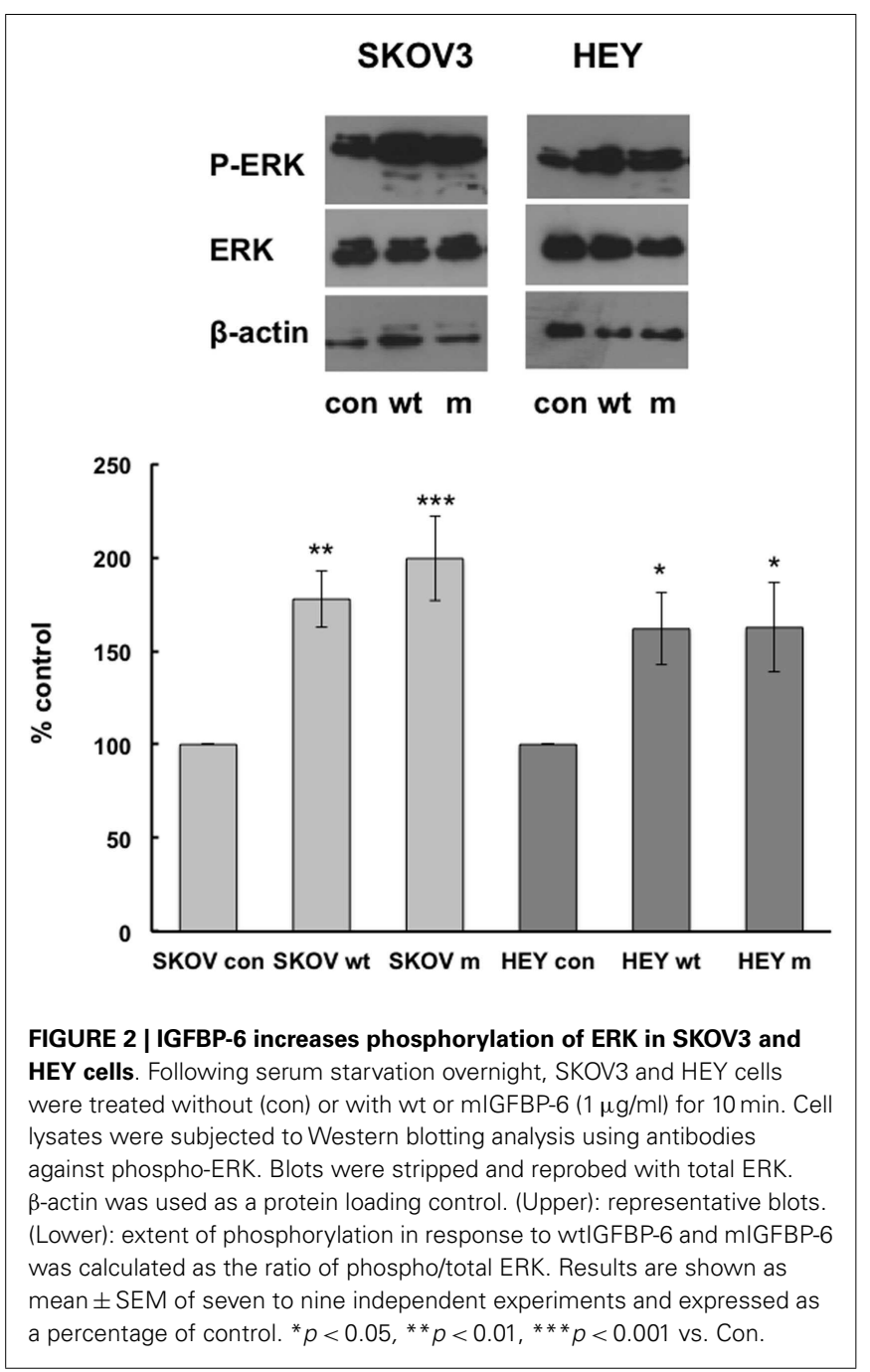

we compared activation of these pathways in HEY and SKOV3 cells. Wt and mIGFBP-6, respectively, increased ERK phosphorylation in SKOV3 cells to $178 \pm 15 \%(p<0.01)$ and $199 \pm 22 \%$ $(p<0.001)$ of control (Figure 2$)$. Similarly, wt and mIGFBP6, respectively, increased ERK phosphorylation in HEY cells to $162 \pm 19 \%(p<0.05)$ and $163 \pm 24 \%(p<0.05)$ of control.

wtIGFBP-6 also increased JNK phosphorylation in SKOV3 and HEY cells to $253 \pm 61 \%(p<0.05)$ and $239 \pm 66 \%(p<0.05)$ of control, respectively (Figure 3). In contrast, mIGFBP-6 significantly increased JNK phosphorylation to $176 \pm 19 \%(p<0.001)$ of control in SKOV3 cells but not in HEY cells $(123 \pm 13 \%$ of control, NS).

Phosphorylation of p38 MAPK was not detected in either cell line under basal conditions or following incubation with wt or mIGFBP-6 (results not shown).

\section{EFFECTS OF ERK AND JNK PATHWAY INHIBITORS ON IGFBP-6-INDUCED MIGRATION IN OVARIAN CANCER CELLS}

PD98059, an inhibitor of ERK1/2 activation, and SP600125, a JNK inhibitor, were used to study the roles of MAPK pathways in IGFBP-6-induced ovarian cancer cell migration. These inhibitors 


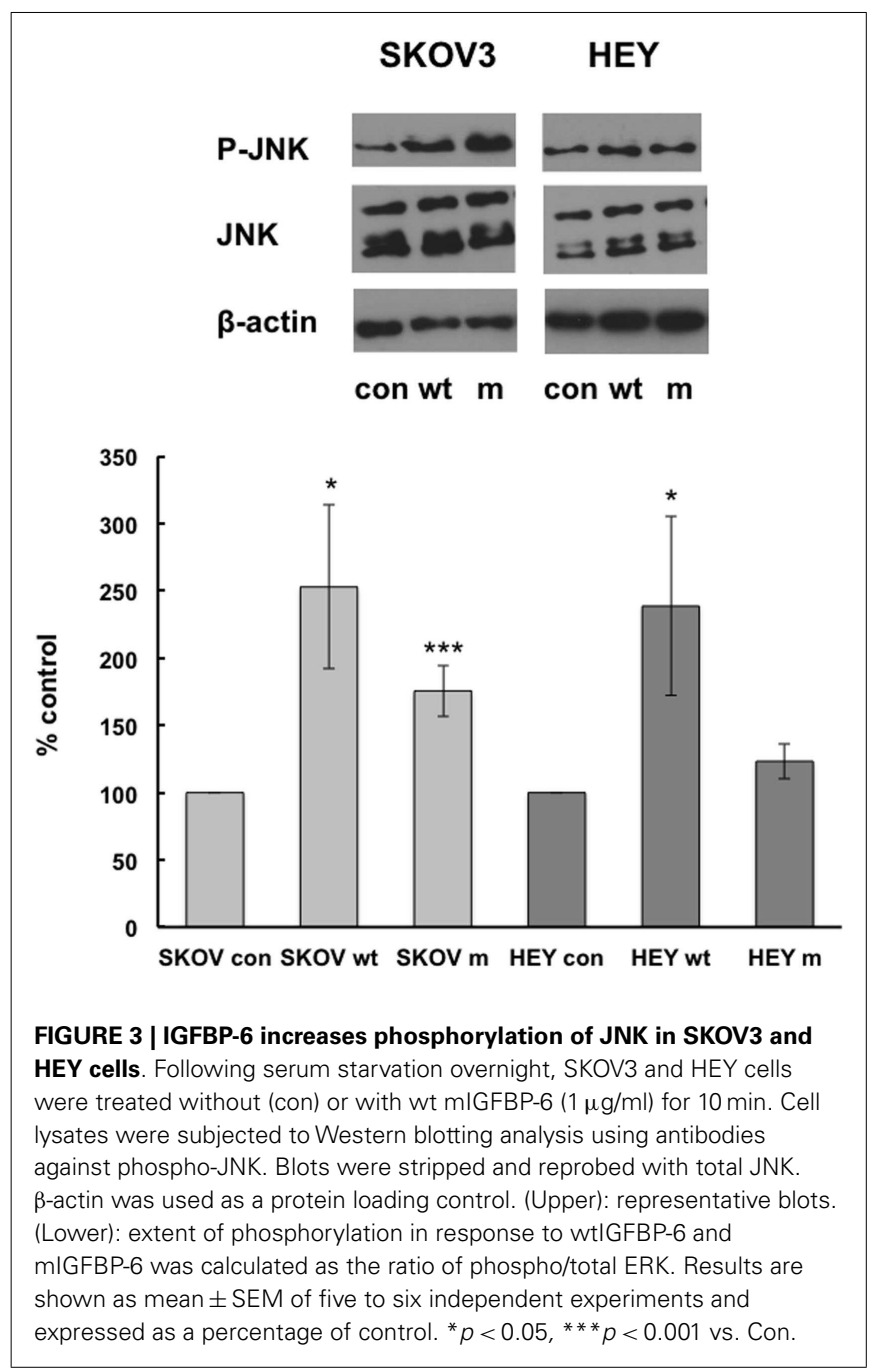

were shown to, respectively, decrease ERK and JNK phosphorylation in each cell line at the concentration used $(30 \mu \mathrm{M}$, results not shown).

In SKOV3 cells, neither inhibitor had a significant effect on basal migration (Figure 4). PD98059 partially inhibited wtIGFBP6 -induced migration from $347 \pm 22$ to $215 \pm 24 \%$ of control $(p<0.001)$. This inhibitor had a similar effect on mIGFBP-6induced migration ( $214 \pm 5$ vs. $353 \pm 9 \%$ of control, $p<0.001)$. SP600125 also partially abrogated SKOV3 cell migration induced by wtIGFBP-6 (223 \pm 16 vs. $347 \pm 22 \%$ of control, $p<0.001)$ and mIGFBP-6 (203 \pm 18 vs. $353 \pm 9 \%$ of control, $p<0.001)$.

In HEY cells, both inhibitors decreased basal migration by $\sim 30 \%(p<0.001$, Figure 4). Despite this, PD98059 partially restored migration in the presence of wtIGFBP-6 (83 \pm 3 vs. $61 \pm 3 \%$ of control, $p<0.001)$ and mIGFBP- 6 ( $86 \pm 2$ vs. $65 \pm 3 \%$ of control, $p<0.001)$. SP600125 also partially restored migration in the presence of wtIGFBP- 6 ( $74 \pm 5$ vs. $61 \pm 3 \%$ of control, $p<0.01)$, although the effect was less potent than that of PD98059 $(p<0.05)$. SP600125 had no effect on mIGFBP-6induced inhibition of HEY cell migration ( $64 \pm 3$ vs. $65 \pm 3 \%$ of control, NS).

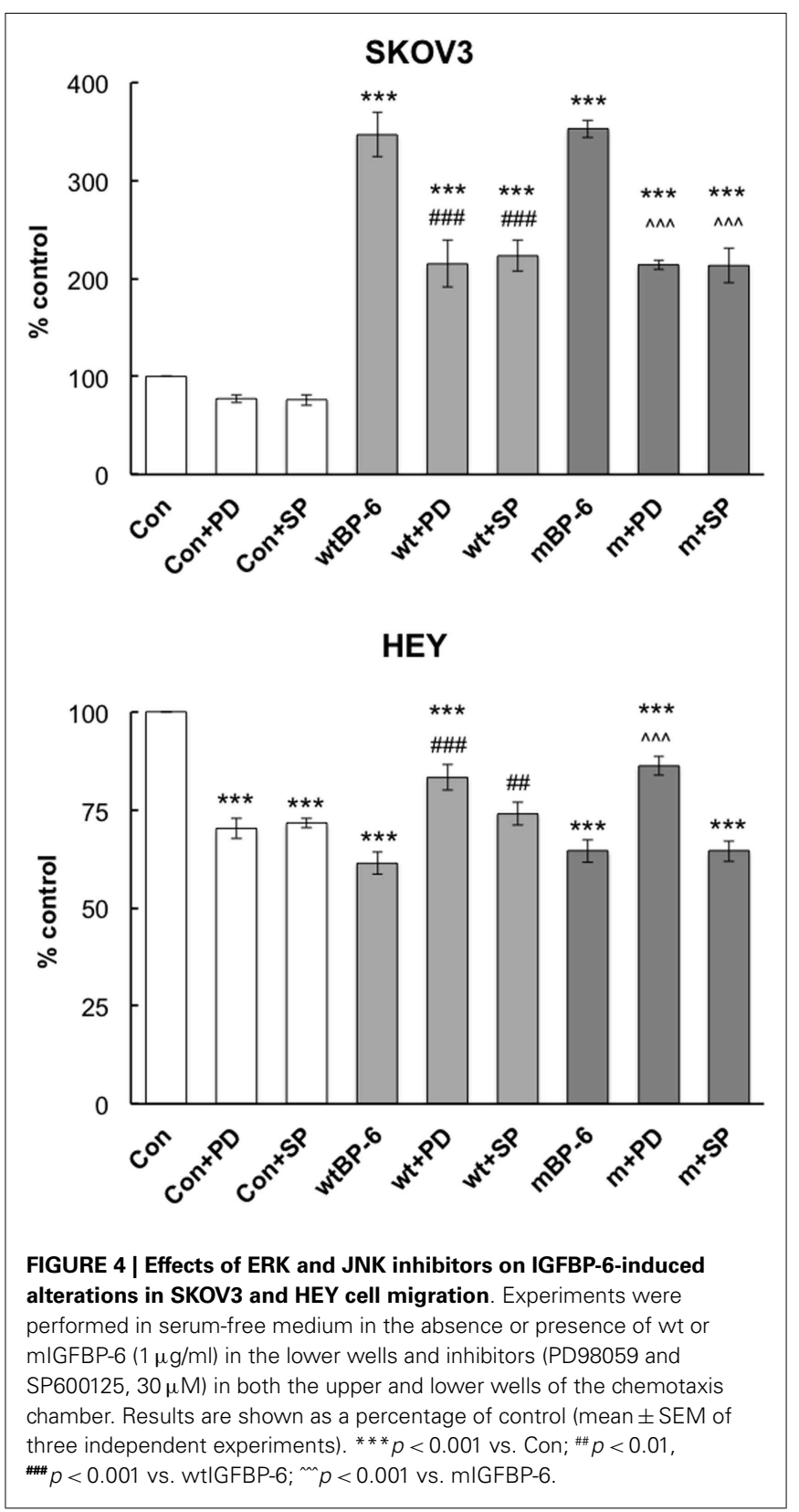

Since both inhibitors had partial effects on IGFBP-6-induced changes in migration in each cell line, the effects of a combination of the two inhibitors were studied to determine whether it would completely abolish migration. However, the combination resulted in significant toxicity in both cell lines (results not shown).

\section{DISCUSSION}

The findings of this study showed that IGFBP-6 increased migration of SKOV 3 ovarian cancer cells in an IGF-independent manner, which is similar to our previous findings in rhabdomyosarcoma and colon cancer cells (9-11). However, in contrast to these cell lines, IGFBP- 6 inhibited migration of HEY ovarian cancer cells. IGF-II reversed the inhibitory effects of wt but not mutant IGFBP6 in these cells, suggesting that IGFBP- 6 inhibited migration by 
both IGF-dependent and IGF-independent mechanisms. Wt and mutant IGFBP-6 increased ERK and JNK phosphorylation in both cell lines, whereas mutant IGFBP-6 only increased ERK phosphorylation in HEY cells. Inhibitors of ERK and JNK partially inhibited the migratory effects of wt and mIGFBP-6 in SKOV3 cells, whereas the ERK inhibitor partially restored wt and mIGFBP6 -induced inhibition of HEY cell migration. The JNK inhibitor had a lesser effect on the actions of wtIGFBP- 6 and no significant effect on the actions of mIGFBP- 6 in HEY cells. The latter is consistent with the lack of effect of mIGFBP-6 on JNK phosphorylation in these cells.

We previously showed that IGFBP-6-induced migration of rhabdomyosarcoma cells is dependent on activation of MAP kinase pathways. In RD rhabdomyosarcoma cells, IGFBP-6 transiently increased phosphorylation of p38 MAPK, whereas ERK was constitutively activated and IGFBP-6 had no further effect (9). Specific p38 and ERK inhibitors completely abolished mIGFBP6 -induced RD cell migration as did p38 knockdown. In contrast, the JNK pathway appeared to have no role in IGFBP-6-induced migration of these cells. The pattern of MAPK activation was different in Rh30 rhabdomyosarcoma cells, which derive from a distinct tumor subtype (10). IGFBP-6 increased phosphorylation of ERK and JNK, but had no effect on p38 phosphorylation in these cells. ERK inhibition abolished mIGFBP-6-induced migration as did a p38 inhibitor, despite IGFBP-6 not inducing p38 phosphorylation. A JNK inhibitor also partially inhibited IGFBP6-induced Rh30 cell migration. These and other findings suggested that crosstalk among MAP kinase pathways played an important role in IGFBP-6-induced cell migration.

MAP kinases are also implicated in ovarian cancer cell migration. MAP4K4 increased SKOV3 cell migration via activation of JNK but not ERK or p38 MAP kinases (23). ERK and JNK were also implicated in mesothelin-stimulated migration of ovarian cancer cells (24), whereas JNK but not ERK or p38 MAP kinase was involved in $\mathrm{GnRH}$-induced ovarian cancer migration (25). Interestingly, the latter study included OVCAR-3 cells, which did not migrate under any conditions in the current study; the reasons for the different responses are unclear but may relate to specific tissue culture conditions. Nevertheless, these findings are consistent with the present study showing that MAP kinase inhibition decreases IGFBP-6-induced migration of SKOV3 cells.

Although MAP kinase activation is associated with increased migration of many cancer cell lines, they may also inhibit this process in some circumstances. For example, ERK activation inhibits neutrophil migration whereas p38 MAP kinase enhances it (26). Similarly, ERK activation mediates CXCL1-induced inhibition of airway smooth muscle cell migration (27). These findings are consistent with those of the present study showing that ERK inhibition partially reversed IGFBP-6-induced inhibition of HEY cell migration.

MAP kinase pathways are not the only signaling pathways involved in cell migration. For example, the PI3 kinase/Akt pathway also mediates migration of some cells (28) including ovarian cancer cells (29). We performed preliminary time-course experiments to determine the effects of wt and mIGFBP- 6 on Akt phosphorylation. There was no effect in SKOV cells but there appeared to be an increase in HEY cells (results not shown). However, these results were highly variable and do not explain the inhibitory effect of IGFBP-6 on HEY cell migration. Further, we have previously found that Akt was not involved in IGFBP-6-induced rhabdomyosarcoma cell migration (10).

We showed that IGFBP-6-induced migration of rhabdomyosarcoma cells is dependent on binding to prohibitin-2 (11). Knockdown of prohibitin-2 abrogated IGFBP-6-induced migration of these cells without perturbing IGFBP-6-induced phosphorylation of ERK or JNK, suggesting that its effect was downstream or independent of MAP kinases (11). The ovarian cancer cell lines used in the present study express prohibitin-2 (results not shown), so it would be of interest to determine whether this protein is involved in the migratory responses observed in the present study.

Other IGFBPs have been shown to have context-specific differences in IGF-independent actions. For example, IGFBP-3 inhibited or enhanced EGF-dependent proliferation of breast epithelial cells depending on whether or not fibronectin was used to coat tissue culture plates (30). In contrast with the present study, IGFBP3 also had differential effects on ERK phosphorylation in these breast cells. A number of other studies have suggested that interactions of IGFBP-3 with other modulators including GRP78 and the sphingolipid rheostat may also play a role in these differential responses (31). Future studies of potential interactions between IGFBP- 6 and these modulators would be of interest.

In conclusion, this study has shown differential effects of IGFBP-6 on migration of two ovarian cancer cell lines. IGFBP6-dependent changes in migration of both cell lines were accompanied by MAP kinase pathway activation, so that this cannot explain the opposite direction of the migratory responses. IGFBP6 inhibits the actions of IGF-II (7) and angiogenesis by an IGFindependent pathway (8), and both of these may contribute to its anti-tumorigenic effects. However, promotion of migration may be pro-tumorigenic, so further studies to determine the mechanisms underlying the differential effects of IGFBP- 6 on migration in these cell lines would help in developing an IGFBP-6-based therapeutic for IGF-II-dependent cancers. These studies could include determining differences in the molecular signatures of these cell lines, which may in turn suggest additional potential therapeutic targets and/or biomarkers of tumor aggressiveness. Metastasis is a complex, multistage process, so studying the effects of IGFBP-6 on other aspects such as cell adhesion would also be of interest. Finally, once the determinants of the promigratory actions of IGFBP-6 are understood, combination therapies including an "optimized" IGFBP-6 molecule and an IGF-I receptor inhibitor may synergistically provide dual blockade of the IGF pathway together with beneficial IGF-independent actions of the binding protein.

\section{ACKNOWLEDGMENTS}

This study was funded by a project grant from Cancer Council Victoria.

\section{REFERENCES}

1. Clemmons DR. Modifying IGF1 activity: an approach to treat endocrine disorders, atherosclerosis and cancer. Nat Rev Drug Discov (2007) 6(10):821-33. doi: $10.1038 / \mathrm{nrd} 2359$

2. Pollak $M$. The insulin and insulin-like growth factor receptor family in neoplasia: an update. Nat Rev Cancer (2012) 12(3):159-69. doi:10.1038/nrc3215 
3. Bach LA, Headey SJ, Norton RS. IGF-binding proteins - the pieces are failing into place. Trends Endocrinol Metab (2005) 16(5):228-34. doi:10.1016/j.tem. 2005.05.005

4. Baxter RC. IGF binding proteins in cancer: mechanistic and clinical insights. Nat Rev Cancer (2014) 14(5):329-41. doi:10.1038/nrc3720

5. Bach LA. Insulin-like growth factor binding protein-6: the "forgotten" binding protein? Horm Metab Res (1999) 31(2-3):226-34. doi:10.1055/s-2007-978723

6. Bach LA. IGFBP-6 five years on; not so 'forgotten'? Growth Horm IGF Res (2005) 15(3):185-92. doi:10.1016/j.ghir.2005.04.001

7. Bach LA, Fu P, Yang Z. Insulin-like growth factor-binding protein-6 and cancer. Clin Sci (2013) 124(4):215-29. doi:10.1042/CS20120343

8. Zhang C, Lu L, Li Y, Wang X, Zhou J, Liu Y, et al. IGF binding protein-6 expression in vascular endothelial cells is induced by hypoxia and plays a negative role in tumor angiogenesis. Int J Cancer (2012) 130:2003-12. doi:10.1002/ijc.26201

9. Fu P, Thompson JA, Bach LA. Promotion of cancer cell migration: an insulinlike growth factor (IGF)-independent action of IGF-binding protein-6. J Biol Chem (2007) 282(31):22298-306. doi:10.1074/jbc.M703066200

10. Fu P, Liang GJ, Khot SS, Phan R, Bach LA. Cross-talk between MAP kinase pathways is involved in IGF-independent, IGFBP-6-induced Rh30 rhabdomyosarcoma cell migration. J Cell Physiol (2010) 224(3):636-43. doi:10.1002/jcp.22156

11. Fu P, Yang Z, Bach LA. Prohibitin-2 binding modulates insulin-like growth factor binding protein-6 (IGFBP-6)-induced rhabdomyosarcoma cell migration. J Biol Chem (2013) 288:29890-900. doi:10.1074/jbc.M113.510826

12. Australian Institute of Health and Welfare \& Cancer Australia 2012. Gynaecological Cancers in Australia: an overview. Cancer series no. 70. Cat. no. CAN 66. Canberra: AIHW (2012).

13. Prevention CfDCa. Gynecologic Cancers. (2013). Available from: http://www. cdc.gov/cancer/ovarian/statistics/

14. Bruchim I, Werner H. Targeting IGF-1 signaling pathways in gynecologic malignancies. Expert Opin Ther Targets (2013) 17(3):307-20. doi:10.1517/14728222. 2013.749863

15. Sayer RA, Lancaster JM, Pittman J, Gray J, Whitaker R, Marks JR, et al. High insulin-like growth factor-2 (IGF-2) gene expression is an independent predictor of poor survival for patients with advanced stage serous epithelial ovarian cancer. Gynecol Oncol (2005) 96(2):355-61. doi:10.1016/j.ygyno.2004.10.012

16. Beauchamp MC, Yasmeen A, Knafo A, Gotlieb WH. Targeting insulin and insulin-like growth factor pathways in epithelial ovarian cancer. J Oncol (2010) 2010:257058. doi:10.1155/2010/257058

17. Walker G, MacLeod K, Williams ARW, Cameron DA, Smyth JF, Langdon SP. Insulin-like growth factor binding proteins IGFBP3, IGFBP4, and IGFBP5 predict endocrine responsiveness in patients with ovarian cancer. Clin Cancer Res (2007) 13(5):1438-44. doi:10.1158/1078-0432.CCR-06-2245

18. Bahrani-Mostafavi Z, Tickle TL, Zhang J, Bennett KE, Vachris JC, Spencer $\mathrm{MD}$, et al. Correlation analysis of HOX, ERBB and IGFBP family gene expression in ovarian cancer. Cancer Invest (2008) 26(10):990-8. doi:10.1080/ 07357900802074349

19. Gunawardana CG, Kuk C, Smith CR, Batruch I, Soosaipillai A, Diamandis EP. Comprehensive analysis of conditioned media from ovarian cancer cell lines identifies novel candidate markers of epithelial ovarian cancer. J Proteome Res (2009) 8(10):4705-13. doi:10.1021/pr900411g

20. Lin BY, White JT, Wu J, Lele S, Old LJ, Hood L, et al. Deep depletion of abundant serum proteins reveals low-abundant proteins as potential biomarkers for human ovarian cancer. Proteomics Clin Appl (2009) 3(7):853-61. doi:10.1002/prca.200800141

21. Shaw TJ, Senterman MK, Dawson K, Crane CA, Vanderhyden BC. Characterization of intraperitoneal, orthotopic, and metastatic xenograft models of human ovarian cancer. Mol Ther (2004) 10(6):1032-42. doi:10.1016/j.ymthe. 2004.08.013

22. Gallicchio MA, Kneen M, Hall C, Scott AM, Bach LA. Overexpression of insulinlike growth factor binding protein-6 inhibits rhabdomyosarcoma growth in vivo. Int J Cancer (2001) 94(5):645-51. doi:10.1002/ijc.1519

23. Collins CS, Hong J, Sapinoso L, Zhou Y, Liu Z, Micklash K, et al. A small interfering RNA screen for modulators of tumor cell motility identifies MAP4K4 as a promigratory kinase. Proc Natl Acad Sci U S A (2006) 103(10):3775-80. doi:10.1073/pnas.0600040103

24. Chang MC, Chen CA, Chen PJ, Chiang YC, Chen YL, Mao TL, et al. Mesothelin enhances invasion of ovarian cancer by inducing MMP-7 through MAPK/ ERK and JNK pathways. Biochem J (2012) 442(2):293-302. doi:10.1042/ BJ20110282

25. Cheung LW, Leung PC, Wong AS. Gonadotropin-releasing hormone promotes ovarian cancer cell invasiveness through c-Jun NH2-terminal kinase-mediated activation of matrix metalloproteinase (MMP)-2 and MMP-9. Cancer Res (2006) 66(22):10902-10. doi:10.1158/0008-5472.CAN-06-2217

26. Liu X, Ma B, Malik AB, Tang H, Yang T, Sun B, et al. Bidirectional regulation of neutrophil migration by mitogen-activated protein kinases. Nat Immunol (2012) 13(5):457-64. doi:10.1038/ni.2258

27. Al-Alwan LA, Chang Y, Rousseau S, Martin JG, Eidelman DH, Hamid Q. CXCL1 inhibits airway smooth muscle cell migration through the decoy receptor duffy antigen receptor for chemokines. J Immunol (2014) 193(3):1416-26. doi:10.4049/jimmunol.1302860

28. Kolsch V, Charest PG, Firtel RA. The regulation of cell motility and chemotaxis by phospholipid signaling. J Cell Sci (2008) 121:551-9. doi:10.1242/ jcs.023333

29. Whitley BR, Beaulieu LM, Carter JC, Church FC. Phosphatidylinositol 3kinase/Akt regulates the balance between plasminogen activator inhibitor-1 and urokinase to promote migration of SKOV-3 ovarian cancer cells. Gynecol Oncol (2007) 104(2):470-9. doi:10.1016/j.ygyno.2006.08.048

30. McIntosh J, Dennison G, Holly JMP, Jarrett C, Frankow A, Foulstone EJ, et al. IGFBP-3 can either inhibit or enhance EGF-mediated growth of breast epithelial cells dependent upon the presence of fibronectin. J Biol Chem (2010) 285(50):38788-800. doi:10.1074/jbc.M110.177311

31. Johnson MA, Firth SM. IGFBP-3: a cell fate pivot in cancer and disease. Growth Horm IGF Res (2014) 24(5):164-73. doi:10.1016/j.ghir.2014.04.007

Conflict of Interest Statement: The authors declare that the research was conducted in the absence of any commercial or financial relationships that could be construed as a potential conflict of interest.

Received: 28 October 2014; paper pending published: 26 November 2014; accepted: 14 December 2014; published online: 05 January 2015.

Citation: Yang $Z$ and Bach LA (2015) Differential effects of insulin-like growth factor binding protein-6 (IGFBP-6) on migration of two ovarian cancer cell lines. Front. Endocrinol. 5:231. doi: 10.3389/fendo.2014.00231

This article was submitted to Cancer Endocrinology, a section of the journal Frontiers in Endocrinology.

Copyright (c) 2015 Yang and Bach. This is an open-access article distributed under the terms of the Creative Commons Attribution License (CC BY). The use, distribution or reproduction in other forums is permitted, provided the original author(s) or licensor are credited and that the original publication in this journal is cited, in accordance with accepted academic practice. No use, distribution or reproduction is permitted which does not comply with these terms. 